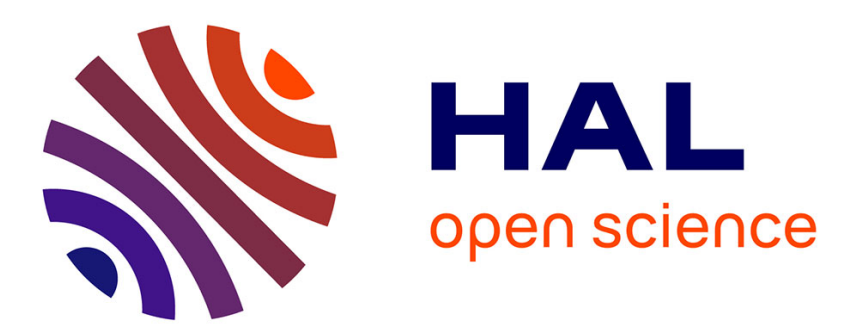

\title{
First steps towards a full integrated cad system for electrical machines
}

\author{
Carole Hénaux, Stéphan Astier, Yvan Lefèvre, Michel Lajoie-Mazenc
}

\section{To cite this version:}

Carole Hénaux, Stéphan Astier, Yvan Lefèvre, Michel Lajoie-Mazenc. First steps towards a full integrated cad system for electrical machines. COMPEL: The International Journal for Computation and Mathematics in Electrical and Electronic Engineering, 1995, vol. 14 ( $\left.\mathrm{n}^{\circ} 4\right)$, pp. 151-155. 10.1108/eb051933 . hal-01664747

\section{HAL Id: hal-01664747 https://hal.science/hal-01664747}

Submitted on 15 Dec 2017

HAL is a multi-disciplinary open access archive for the deposit and dissemination of scientific research documents, whether they are published or not. The documents may come from teaching and research institutions in France or abroad, or from public or private research centers.
L'archive ouverte pluridisciplinaire HAL, est destinée au dépôt et à la diffusion de documents scientifiques de niveau recherche, publiés ou non, émanant des établissements d'enseignement et de recherche français ou étrangers, des laboratoires publics ou privés. 


\section{OATAO \\ Open Archive Toulouse Archive Ouverte}

Open Archive TOULOUSE Archive Ouverte (OATAO)

OATAO is an open access repository that collects the work of Toulouse researchers and makes it freely available over the web where possible.

This is an author-deposited version published in :

http://oatao.univ-toulouse.fr/

Eprints ID : 19304

To link to this article : DOI:10.1108/eb051933

URL : https://doi.org/10.1108/eb051933

To cite this version : Henaux, Carole and Lefèvre, Yvan towards a full integrated cad system for electrical machines. (1995) COMPEL: The International Journal for Computation and Mathematics in Electrical and Electronic Engineering, vol. $14\left(\mathrm{n}^{\circ}\right.$ 4). pp. 151-155. ISSN 0332-1649

Any correspondence concerning this service should be sent to the repository administrator: staff-oatao@listes-diff.inp-toulouse.fr 


\title{
FIRST STEPS TOWARDS A FULL INTEGRATED CAD SYSTENI FOR ELECTRICAL MIACHINES
}

\author{
C. Pertusa, S. Astier, Y. Lefevre and M. Lajoie-Mazenc \\ Laboratoire d'Electrotechnique et d'Electronique Industrielle (LEEI) \\ URA CNRS no 847, 2 rue Camichel 31071 Toulouse cedex, France
}

\begin{abstract}
An approach for electrical machines design by using a software which links the sizing procedure to the magnetic field computation is presented in this paper. After reviewing the principles of an electrical machine general design, the process of the development and the use of a special link between the dimensions data and the magnetic field computation is described. The whole solution procedure is conducted automatically. Any change on the machine dimensions can be made and the sequence of the CAD tasks can be prepared and run automatically without any user intervention. The whole procedure is applied to a comparative study of different structures of permanent magnets synchronous motors.
\end{abstract}

\section{Introduction}

In the general design of electrical machines, three fundamental stages are required: the analysis of the specifications, the sizing procedure and, before the fabrication of prototypes, the use of a magnetic field computation software to analyse the behaviour of the projected machine. In section one, we introduce the fundamental principles of these stages. When one or several machines must be optimised, a large amount of field calculations may be required, and thus, the practical application of magnetic field computation software for iterative design is limited by the amount of user interaction required. This is why an automatic link between the dimensions data and the solving of the magnetic field equations is really necessary to assist the user during the design procedure. Section two presents the principles of the magnetic field computation and the method used to make this automatic link. As an example of its use, in section three a comparative study of four structures of permanent magnet motors is presented.

\section{General design procedure of electrical machines}

The electrical machine design is initiated by the analysis of the specifications which permits to formulate the characteristics that must be matched. These characteristics may be: the electrical characteristics such as the power, the voltage or current, the thermal characteristics, the electromechanical characteristics such as the torque versus the speed. A set of constraints such as minimal cost of fabrication, limited size, noise or vibration level, under which the motor must 
operate, may also be formulated. The analysis of the specifications is based on the expert knowledge of the designers and helps to choose different structures of motors and their electronic power supply.

After the choice of this set of structures, the designer proceeds to a first computation of their dimensions. This computation begins, for each structure, with the definition of reference variables such as the rated torque or the rated speed and a set of preliminary parameters. Reference variables and preliminary parameters can be linked by simple analytical expressions[1]. Further relations between dimensions and electromagnetic variables can be obtained by building magnetic equivalent circuits based on the Ampere's theorem and the principle of the conservation of flux. Supply waveshapes can be taken into account.

Once the chosen structures are sized, their electromagnetical characteristics must be calculated in order to know if the performances required by the application are reached. These characteristics can be calculated with a very good accuracy by magnetic field computation software based on finite element method[2] which can take into account the saturation of magnetic materials, eddy currents and the movement of the rotor. Yet, their uses in a design procedure are limited by the numerous wearisome tasks needed in an iterative and comparative design. An automatic link between the sizing procedure and the software is necessary to overcome this problem.

\section{Computation of the electromagnetical characteristics of an electrical machine by means of a finite element method}

In most of software based on finite element method, the calculation of the electromagnetical characteristics of magnetic device needs the following tasks: preprocessing (definition of the magnetic field problem to be solved (1)), meshing (2), solving the magnetic field problem (3), postprocessing to exploit the results (4). Generally an automatic meshing is available. For a given type of electrical machine, the tasks 3 and 4 can be run automatically by means of system commands which redirect the entry of each task to an appropriate file response. One file response for each calculation and for each structure is needed.

The first task which is generally run interactively by the user must be analysed carefully before developing an automatic procedure of the definition of magnetic problem. First the user defines the geometry of the device by means of a graphic interface. In this step the user enters the coordinates of some key points and from these points builds the lines that give shape to the studied magnetic structure. Afterdefining the geometry, the materials chosen from a material library are introduced and linked with the appropriate part of the model. In a 2D finite element code each part consists of a closed area delimited by lines defined themselves by key points. In the case of electrical machines, the parts can be made of: non magnetic materials (air gap, slots), magnetic materials (teeth) or magnetized materials (permanent magnets). Then the user enters the sources of magnetic fields by describing the winding of the machine. In the fourth step the boundary conditions are specified and the user must fix the cutting out of some lines in order to define the meshing of some parts of the structure. Depending on the calculation to be run, specific meshing is necessary to improve the accuracy of the results. At the end of this task all the dataentered by the user are stored in a file that we can call a premesh file. In the finite element code $\operatorname{EFCAD[3],~which~is~available~and~developed~}$ in our laboratory, the data in this premesh file can be parametered by the key points on which all the data are connected. The structure of these data can be seen on Figure 1.

From this kind of structure, we can see that it is easy to change the dimensions of a machine already having a premesh file. For that the user has only to change the coordinates of the key points. 
key poirss $\left[\begin{array}{l}P_{l} \\ P_{2} \\ \cdot \\ P_{n p}\end{array} \quad \Rightarrow\right.$ lines $\left[\begin{array}{l}L_{l}: P_{l} P_{j} \\ L_{2}: P_{k} P_{i} \\ \\ L_{n l}: P_{8} P_{n}\end{array}\right.$

dosed area $\left[\begin{array}{c}A_{1}: L_{1} L_{j} \ldots L_{k} \\ A_{2}: L_{n} L_{\alpha} \ldots L_{B} \\ \cdot \\ \cdot \\ \cdot \\ A_{m a}: L_{b} L_{c} \ldots L_{d} \\ \Downarrow\end{array} \quad\right.$ asaurces and matrials $\left\{\begin{array}{c}A_{1}: M_{l} S_{3} \\ A_{2}: M_{2} S_{d} \\ \cdot \\ \cdot \\ \cdot \\ A_{n a}: M_{j} S_{k}\end{array}\right.$

boundary conditions $\mid \begin{gathered}F_{1}: L_{\alpha} L_{\beta} L_{\chi} \\ F_{2}: L_{\varepsilon} L_{\zeta} L_{\theta} \\ \cdot \\ \cdot \\ \cdot \\ F_{n h}: L_{\nu} L_{r} L_{n}\end{gathered}$

Figure 1. Structure of data in the premesh file.

\section{Automatic link between the sizing of structures and the computation of their electromechanical characteristics}

The link has been created with the purpose of being able to study easily and quickly any machine from the sizing procedure to the computation of the electromagnetical characteristics[4]. This link is based on establishing a library of referential structures which contains the premesh files of the whole set of structures available in the sizing module. Once the sizing of the studied machine is achieved, the dimensions data are treated and from the premesh file of the appropriate referential structure, the premesh file of the new machine is created. From the dimensions data of this machine, a computation module enables to obtain the new coordinates of the key points of the premesh file. The other table concerning the lines, areas, materials, winding, sources and boundary conditions remain unchanged.

With this link in the whole procedure design, each structure is characterised by an equivalent magnetic circuit scheme from which the machine dimensions can be calculated, a reference premesh file and a program for the computation of the coordinates of the key points. These two last tasks are integrated in a main program which builds the premesh file and the response files needed to run automatically the problem definition and the calculation of the electromagnetical characteristics.

\section{Comparative study}

Integrated in a module of dimensions parametric variation, this automatic definition allows us easily to carry out a comparative study on four different structures of permanent magnet motors: structure with and without polar pieces, with interior and exterior rotor. The aim consists in the comparison of the variation of their load torque versus the variations of the magnet width and depth. From the dimensions data of the machine, the width $\mathrm{Xl}$ and the depth $\mathrm{X} 2$ vary about \pm 5 per cent. With the resulting three levels of variation, 36 problem definitions and magnetic field computations are needed to obtain these results for the whole study (Figure 2, Figure 3 and Table 1). 


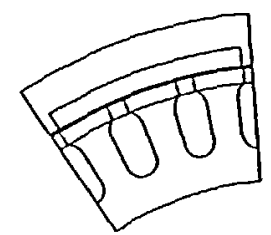

$\mathrm{ml}$ : exterior rotor

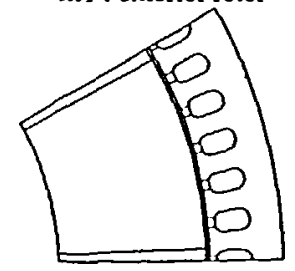

$\mathrm{m} 3$ : polar pieces and interior rotor

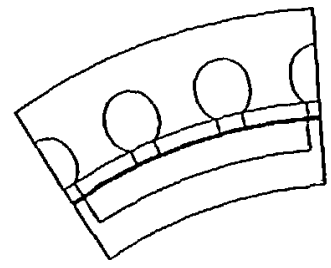

$\mathrm{m} 2$ : interior rotor

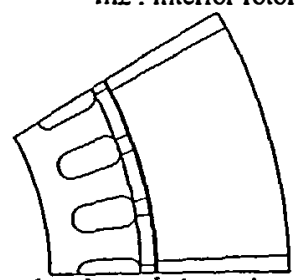

$\mathrm{m} 4$ : polar pieces and exterior rotor

Figure 2. Schema of the studied motors.

$$
\mathrm{xi} 1=\mathrm{xi} 2-5 \% \mathrm{xi} 2 \text { and } \mathrm{xi} 3=\mathrm{xi} 2+5 \% \mathrm{xi} 2
$$

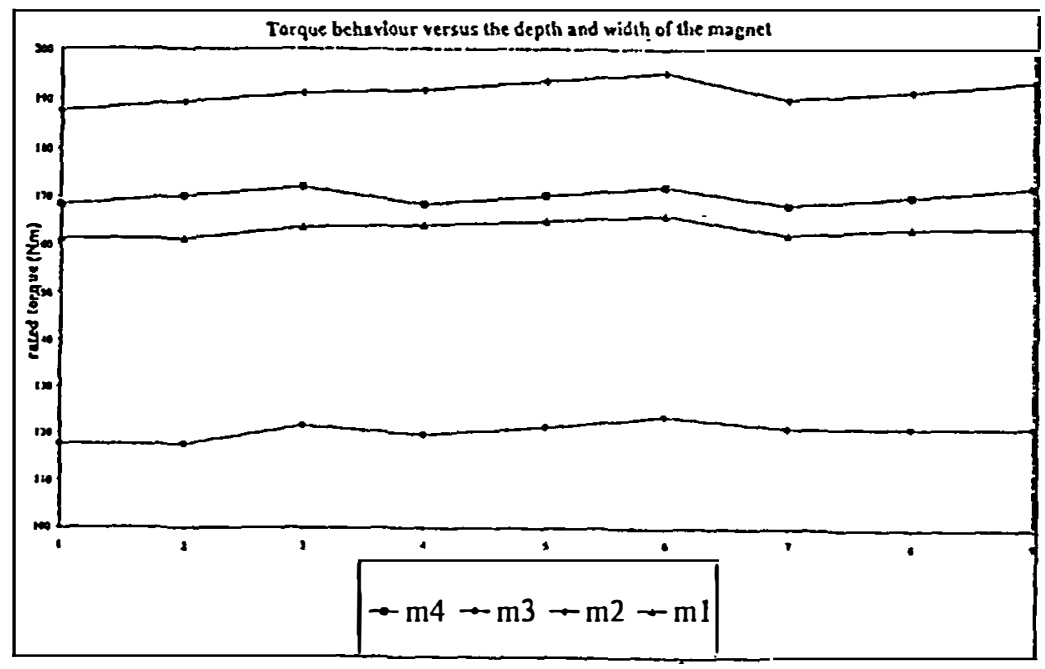

Figure 3. Simulations results.

Table I. The parametric variation.

\begin{tabular}{|c|l|l|l|l|l|l|l|l|l|}
\hline simulation & $\mathrm{n}^{\circ} 1$ & $\mathrm{n}^{\circ} 2$ & $\mathrm{n}^{\circ} 3$ & $\mathrm{n}^{\circ} 4$ & $\mathrm{n}^{\circ} 5$ & $\mathrm{n}^{\circ} 6$ & $\mathrm{n}^{\circ} 7$ & $\mathrm{n}^{\circ} 8$ & $\mathrm{n}^{\circ} 9$ \\
\hline $\mathrm{X} 1$ & $\mathrm{x} 11$ & $\mathrm{x} 12$ & $\mathrm{x} 13$ & $\mathrm{x} 11$ & $\mathrm{x} 12$ & $\mathrm{x} 13$ & $\mathrm{x} 11$ & $\mathrm{x} 12$ & $\mathrm{x} 13$ \\
\hline $\mathrm{X} 2$ & $\mathrm{x} 21$ & $\mathrm{x} 21$ & $\mathrm{x} 21$ & $\mathrm{x} 22$ & $\mathrm{x} 22$ & $\mathrm{x} 22$ & $\mathrm{x} 23$ & $\mathrm{x} 23$ & $\mathrm{x} 23$ \\
\hline
\end{tabular}


By the use of the automatic definition and the parametric variation module the user must only give the dimensions data and the width and depth magnet levels of variation of each machine structure. The 36 magnetic field computations are automatically conducted.

\section{Conclusion}

A method for an electrical machine general design from the sizing procedure to the magnetic field computation has been described in this paper. This method, based on an automatic procedure which links the sizing module and the magnetic field computation, is perfectly adapted to any study which requires a large number of magnetic field computations. So, its use can be extended to carry out an optimisation procedure.

\section{References}

[1] Nogarède, B., "Etude de moteurs sans encoches à aimants permanents de forte puissance à basse vitesse", Thèse de doctorat de l'Institut National Polytechnique de Toulouse, 1990.

[2] Nathan, I. and Bastos, J.P.A., Electromagnetics on calculations of fields, Ed Springer Verlag, 1992.

[3] Sadowski, N., "Modelisation des machines électriques à partir de la résolution des équations du champ en tenant compte du mouvement et du circuit d'alimentation (logiciel EFCAD)", Thèse de doctorat de l'Institut National Polytechnique de Toulouse, 1993.

[4] Pertusa, C., Astier, S., Lefevre, Y. and Lajoie-Mazenc, M., "Aided design of electrical machines by field calculation and factorial experiments method”, CBMag'95, Florianopolis, June 1995. 
This article has been cited by:

1. Y. Lefevre, J. Fontchastagner, F. Messine. 2006. Building a CAD system for educational purpose based only on a mesh tool and a finite elements solver. IEEE Transactions on Magnetics 42:4, 1483-1486. [CrossRef]

2. V. Tandon, H. El-MounayriAspects of integrated CAD/CAM for advanced manufacturing 539-546. [CrossRef] 